\title{
Fragile X Newborn Screening: Lessons Learned From a Multisite Screening Study
}

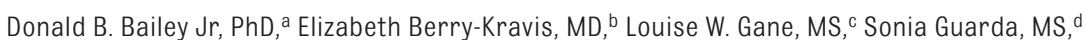

Randi Hagerman, MD, ${ }^{c}$ Cynthia M. Powell, MD, ${ }^{d}$ Flora Tassone, PhD, ${ }^{c}$ Anne Wheeler, PhDa

BACKGROUND: Delays in the diagnosis of children with fragile X syndrome (FXS) suggest the possibility of newborn screening as a way to identify children earlier. However, FXS does not have a proven treatment that must be provided early, and ethical concerns have been raised about the detection of infants who are carriers. This article summarizes major findings from a multisite, prospective, longitudinal pilot screening study.

METHODS: Investigators in North Carolina, California, and Illinois collaborated on a study in which voluntary screening for FXS was offered to parents in 3 birthing hospitals. FXS newborn screening was offered to $>28000$ families to assess public acceptance and determine whether identification of babies resulted in any measurable harms or adverse events. Secondary goals were to determine the prevalence of FMR1 carrier gene expansions, study the consent process, and describe early development and behavior of identified children.

RESULTS: A number of publications have resulted from the project. This article summarizes 10 "lessons learned" about the consent process, reasons for accepting and declining screening, development and evaluation of a decision aid, prevalence of carriers, father participation in consent, family follow-up, and maternal reactions to screening.

concLusions: The project documented public acceptance of screening as well as the challenges inherent in obtaining consent in the hospital shortly after birth. Collectively, the study provides answers to a number of questions that now set the stage for a next generation of research to determine the benefits of earlier identification for children and families.

${ }^{a}$ Center for Newborn Screening, Ethics, and Disability Studies, RTI International, Research Triangle Park, North Carolina; ${ }^{b}$ Department of Neurological Sciences, Rush University Medical Center, Chicago, Illinois; ' MIND Institute, University of California at Davis, Sacramento, California; and dDepartment of Pediatrics, University of North Carolina at Chapel Hill, Chapel Hill, North Carolina

Dr Bailey conceptualized and designed the paper, wrote the first draft of the manuscript, integrated edits from all coauthors, and prepared the final manuscript for submission; Dr Berry-Kravis conceptualized and designed the study, directed all research at the Illinois site, reviewed and revised the manuscript; Ms Gane provided counseling services at the California site and reviewed and revised the manuscript; Ms Guarda was the primary recruiter at the North Carolina site and reviewed and provided input on the manuscript; Dr Hagerman conceptualized and designed the study, directed the clinical research at the California site, and reviewed and revised the manuscript; Dr Powell directed the clinical follow-up at the North Carolina site and reviewed and revised the manuscript; Dr Tassone conceptualized and designed the study, developed the screening test, directed the laboratory analyses at the California site, and reviewed and revised the manuscript; and Dr Wheeler conducted follow-up assessments at the North Carolina site, coordinated data management for the follow-up assessments across all 3 sites, wrote sections of the paper, and reviewed and revised the manuscript; and all authors approved the final manuscript as submitted.

DOI: https://doi.org/10.1542/peds.2016-1159H

Accepted for publication Jan 24, 2017

Address correspondence to Don Bailey, PhD, Center for Newborn Screening, Ethics, and Disability Studies, RTI International, 3040 E. Cornwallis Rd, Research Triangle Park, NC 27709. E-mail: dbailey@rti.org

PEDIATRICS (ISSN Numbers: Print, 0031-4005; Online, 1098-4275). 
Despite the appearance of symptoms during the first year of life and early concerns of parents, timely diagnosis of children with fragile X syndrome (FXS) remains a persistent challenge that has proved difficult to remediate. The average age of diagnosis for boys with the full mutation $(>200$ CGG repeats in the FMR1 gene), who typically have moderate intellectual and developmental delays and a variety of associated conditions, ${ }^{1}$ is around 36 months, essentially unchanged despite a variety of awareness activities and professional guidelines. $^{2-4}$ For families, a late diagnosis can result in repeated physician visits, lack of early intervention services, and, for some, the birth of additional children with FXS before the first is diagnosed.

Parents of affected children strongly support earlier screening, ${ }^{5-7}$ and professionals from several disciplines have generally favorable opinions about earlier identification. ${ }^{8-12}$ Whether newborn screening (NBS) is the answer has been debated, in part because no treatment has been shown to be effective in the earliest years, an essential requirement for statemandated NBS programs. ${ }^{13-15}$ Beyond lack of data on treatment efficacy, NBS for FXS evokes a number of other ethical, policy, and social concerns, ${ }^{16,17}$ one of the most controversial of which is detection of infant "premutation" carriers (55200 CGG repeats). Recent reports recommend that if carrier status is detected in children, results should be returned to parents. ${ }^{18,19}$ But FXS presents an unusual ethical challenge because parents, one of whom will be implicated as a fragile X (FX) carrier, themselves may have a variety of health, cognitive, and emotional problems. Female carriers are at risk for FX-associated primary ovarian insufficiency (FXPOI) ${ }^{20}$ and both sexes are at risk for FX-associated tremor ataxia syndrome (FXTAS). ${ }^{21}$
Some carriers are also at risk for learning problems and brain function abnormalities, autism spectrum features, attention and visual perceptual deficits, and depression or anxiety disorders..$^{22-26}$

In 2008, we received funding from the National Institutes of Health to conduct a prospective, longitudinal pilot study to address some of the concerns about NBS for FXS. We framed the study as the social science equivalent of an early phase clinical trial, typically designed to determine the acceptability of a treatment, tolerable doses, feasibility, and safety, essential information before embarking on a larger efficacy trial. Accordingly, our primary goal was not to prove benefit from screening, but rather to assess public acceptance and determine whether identification of babies resulted in any measurable harm or adverse events. In addition, we had 3 secondary goals: determine the prevalence of FMR1 carrier gene expansion, study the consent process, and describe early development and behavior of identified children.

The study was a partnership between investigators at the University of North Carolina at Chapel Hill (UNC-CH), the University of California Davis (UC-Davis) Medical Center, and Rush University Medical Center (RUMC). Initially, our sites were not linked, because we were preparing separate applications to a request for applications from the Eunice Kennedy Shriver National Institute for Child Health and Human Development for FX research centers. We knew of our respective plans and initially discussed collaboration, but did not link applications because one might be approved and the other not. Once both were funded (University of California Davis and Rush University Medical Center submitted a joint application), we applied for and received a supplement to harmonize recruitment procedures and agree on common outcome measures, but this took considerable time, and thus some aspects of the project differed across sites. However, the general approach was the same. In brief, shortly after giving birth and while still in the hospital, parents were given information about the study and offered voluntary FX NBS. Screening was performed on consented dried blood spots. Families of screen-positive babies were contacted and invited to return for a diagnostic confirmation and genetic counseling. Families were then invited to participate in a longitudinal study assessing maternal outcomes and the development of identified infants.

Both teams used a screening test that detects individuals with FXS and premutation carriers. ${ }^{27} \mathrm{We}$ decided to disclose carrier results for 5 reasons: (1) we wanted to know how many parents would agree to a screening test that detected carriers; (2) it provided an unprecedented opportunity to assess whether any symptoms might be apparent in early childhood; (3) knowing infant carrier status meant that 1 parent was a carrier and other family members may have either a premutation or full mutation, information that could be important to some families for reproductive planning and for potential additional health issues for carriers; (4) it provided the opportunity to study prevalence in a relatively unbiased population; and (5) ultimately, we had no ethical justification for withholding this information from parents.

This article summarizes our major findings, presented as "lessons learned." Our hope is to provide information that might be useful for investigators conducting similar studies on FX or other conditions. We conclude by discussing the challenges inherent in providing evidence needed to evaluate the benefits of NBS for rare disorders. 
LESSON 1: IN-HOSPITAL CONSENT IS POSSIBLE BUT CHALLENGING

The recruitment and consent process is detailed in earlier publications. ${ }^{27,28}$ In brief, a recruiter approached families shortly after birth and asked if they were interested in learning about a research study. If they agreed, the recruiter provided a copy of the consent form and a brochure. Some parents were ready to decide immediately, but most had a few hours to consider, after which, the recruiter returned to ascertain willingness to participate.

The process worked, but the magnitude of burden and the inherent challenges in consenting during this time were substantial. By any standard, asking mothers to consider a research study within a few hours of birth is far from ideal. Prenatal consent would have been preferable, but coordination with all prenatal providers associated with each hospital was not feasible or affordable. We hired our own recruiters because we could not expect hospital staff to convey the complex implications of FXS and previous research had demonstrated lack of follow-through when relying on hospital staff. ${ }^{29}$ Bilingual recruiters were available to talk with the substantial proportion of Spanish-speaking families, and all written materials were available in both English and Spanish. Limited funding meant that we were not always able to recruit at night or on weekends or holidays.

Most NBS today is conducted without consent on the assumption that a public health mandate and the interest of the infant are sufficiently compelling to warrant screening without consent. Although generally well-accepted, mandatory screening has been the subject of considerable debate, ${ }^{30}$ and some have argued that the changing nature of screening may suggest a reconsideration of voluntary consent. ${ }^{31}$ However, the broader challenges of informed consent $^{32}$ and our data suggest that consent for NBS conducted in the hospital will be an enormous informational and logistical burden.

\section{LESSON 2: ALMOST TWO-THIRDS OF FAMILIES AGREED TO HAVE THEIR CHILD SCREENED}

In 2011 we reported initial (15month) findings about parents' decisions to participate at the North Carolina site. ${ }^{28}$ Recruiters approached 2137 mothers, of whom $95.7 \%$ were willing to hear about the study and, of those, $63 \%$ of couples agreed to have their child screened. By the time the project ended in 2014, across all 3 sites, screening was offered to $>28000$ families, with an acceptance rate of $62 \%$ and $>17000$ infants screened.

Our earlier surveys of parents of children with FXS found a higher acceptance of NBS for FXS and for return of results of carrier status $(>80 \%)$ compared with the pilot study. ${ }^{5,6}$ Parents of an affected child are understandably more interested in earlier identification; most would have preferred to avoid a lengthy diagnostic odyssey, but the general public has not had this experience. We conclude that the majority of the population would accept NBS for FXS and for carrier status. But, clearly, a substantial portion do not want NBS or would not be able to decide in the hospital. This finding has implications for other conditions for which there are no proven treatments that must be provided during early childhood. Knowing that more than one-third of families question the desirability of FX NBS significantly weakens any justification for mandatory screening for such conditions until stronger evidence of benefit is demonstrated.

\section{LESSON 3: THE REQUIREMENT TO OBTAIN CONSENT FROM BOTH MOTHERS AND FATHERS PROVIDED AN ADDED CHALLENGE BUT ALSO AN OPPORTUNITY TO DEVELOP GUIDANCE FOR DECISION-MAKING}

We submitted separate institutional review board (IRB) applications for each site. The IRBs differed in their assessment of risks and benefits, with implications for recruitment. The RUMC IRB determined that the study met the standard for greater than minimal risk, but with the potential for direct benefit, a federal code of $\$ 46.405 / \$ 50.52 .33$ The UNC-CH and UC-Davis IRBs determined that the study was greater than minimal risk, but with no potential for direct benefit to the infant and coded the study $\S 46.405 / \S 50.53$. These decisions meant that at those sites, we were required to get permission from both parents, if "reasonably available," whereas only the mothers' permission was needed at RUMC.

A report based on our North Carolina sample found that $68 \%$ of mothers who heard about the study agreed to participate, but the overall acceptance rate dropped to $64 \%$ when fathers were taken into account. ${ }^{34}$ In nearly $20 \%$ of cases, the father was not present in the hospital. Of those, $\sim 60 \%$ were considered "not reasonably available," and we were able to use the mother's consent. In the remaining cases, the father was considered "reasonably available" and was sent a consent form. Of those, only 30\% returned a signed form.

To the best of our knowledge, we are the first to report a detailed analysis of father involvement in the consent process for research purposes involving couples. Throughout the process, we consulted with IRB officials and legal counsel to clarify definitions of "reasonably available" and outline the steps necessary before making a final determination of whether the father's consent was needed. We created an algorithm to help other investigators conducting research in which permission from both parents is required. ${ }^{34}$

Although we do not fully agree with the IRBs that determined there was no potential for direct benefit to the child, we do not have empirical 
data to support that argument. We do agree that, ideally, both parents should be involved in the consent process. FX NBS has the potential to implicate either the mother or the father as a carrier, and the identification of a screenpositive infant inevitably has broader implications for extended family members. Case studies from one of our sites, for example, showed that identifying 1 child can lead to the identification of many extended family members as either premutation carriers or individuals with FXS. ${ }^{35}$ Such extended family ramifications suggest the importance of both parents consenting, but the dual consent requirement raises other ethical issues; for example when the mother clearly wants screening, but the father does not. Regardless, we have shown that obtaining consent from both parents requires substantial time and resources and presents challenging decisions regarding the "reasonably available" standard.

\section{LESSON 4: REASONS FOR ACCEPTING OR DECLINING VARIED ACROSS FAMILIES AND PARTICIPATION WAS ASSOCIATED WITH ETHNICITY}

Why did parents accept or decline screening? In our initial article from the North Carolina site, we reported that the most common reasons for accepting focused on the desire to know important information about their child, belief in the importance of supporting research, and the perception of minimal risk. ${ }^{27}$ Those who declined did not want to worry about their child, had issues with testing very young children, preferred to wait until symptoms appear, or reported that the timing of consent made it difficult for them to decide. African American families were significantly less likely to accept screening. This acceptance rate and the lower participation by African American families remained relatively constant across time and across sites. ${ }^{28}$

We are currently completing a more detailed analysis of reasons for accepting or declining as a function of ethnicity. The RUMC and UC-Davis sites are also completing a more detailed analysis of reasons for consenting or declining.

Our results reflect the majority of parents' basic desire to know anything that might impact the baby as soon as possible, but there is a significant minority who do not need or want to know unless the baby begins to show symptoms. In the absence of a defined treatment that can change the course of development in FXS, both of these viewpoints are reasonable, and thus, ways of approaching screening that can accommodate both perspectives are needed.

\section{LESSON 5: HIGH-QUALITY CONSENT MATERIALS CAN AID INFORMED DECISION-MAKING ABOUT STUDY PARTICIPATION, BUT EVEN THE BEST MATERIALS HAVE LIMITED EFFECTIVENESS IN THE CONTEXT OF IN-HOSPITAL CONSENT}

About 2 years into the project, we decided to change the recruitment brochure, for several reasons. First, fewer than half of parents reported looking at the old brochure, so we wanted to create a new brochure that was more visually appealing. Second, because almost all identified cases were carriers, we wanted to convey more clearly the meaning of carrier status and the likelihood of carrier identification. Third, recognizing the differences in acceptance rate by ethnicity, we wanted to convey pictorially the fact that FX affects all races/ethnicities. Finally, we wanted a tool to help the recruiters support families in making truly informed decisions about study participation.

To guide the development of the new brochure, we drew on the principles of informed decision-making (IDM), a proven approach to develop tools that help people participate in health decisions in ways they prefer. ${ }^{36}$ IDM is typically used when there is $>1$ medically reasonable option to diagnose or treat a health problem. IDM tools provide information and help people clarify their values when making a decision for which there is not one right answer. ${ }^{37}$

We used an iterative process with multiple review points to develop a brochure in accordance with IDM standards. The brochure was colorful and informative, providing clear descriptions of the study, the effects of FXS, and the meaning of carrier status, and it concluded with a balanced set of reasons why parents might or might not want to participate. The brochure received high ratings from an independent review group. In a simulation study, we found that it took women about 6.5 minutes to read the brochure, and they scored an average of $91.1 \%$ correct on a follow-up knowledge test. ${ }^{38}$ Minority and white mothers did not differ in their perceptions of quality of the brochure or trust of the information. We still found that more white (64\%) and Hispanic (75\%) mothers compared with African American mothers (57\%) reported that they would probably agree to screening, but this difference was not statistically significant.

The brochure was translated into Spanish, slight site-specific modifications in the text were made, and all sites began using it. The UNC-CH site used a pre-postintervention design to determine whether the new brochure enabled informed decisions. ${ }^{39}$ We found that families were more likely to look at the new decision aid, but only $14 \%$ of the mothers (as compared with $11 \%$ with the original brochure) reported having read the entire brochure.

With few exceptions, ${ }^{40}$ this is one of the first efforts to use IDM in a 
research context, as opposed to decision-making for the purpose of health care. We are confident that the new brochure was a significant improvement over the original and, if read, would be a great help in supporting informed decisions. We had hoped it would also reduce the time needed by recruiters, but that was not possible given that so few women read it. Our findings reiterate the importance of the context in which consent is requested, and suggest that better materials alone, at least in the format we developed, will not be sufficient to make the consent process more efficient.

\section{LESSON 6: UNLIKE MOST CURRENT NBS TESTS, THE SCREENING METHOD WE USED WAS VIRTUALLY DIAGNOSTIC}

The screening methodology we used is a polymerase chain reaction (PCR)based approach ${ }^{28,41}$ that allows the detection of FMR1 expanded alleles and provides precise data on the allele CGG repeat number, from the normal through the full mutation range, in both sexes. We found consistent agreement between screening data performed from the blood spot cards and PCR-based confirmatory testing performed on whole blood for all the newborns that tested positive (usually within 2-5 CGG repeat lengths). The classification of infants (normal, premutation, full mutation) based on screening data was the same as the final classification based on confirmatory testing, with the exception of 3 infants, resulting from a calibration error in the screening laboratory (not an error in the laboratory test itself).

NBS today often results in a large number of false positives, on the assumption that it is better to identify a child who does not have a disease than to miss an affected infant. We show that as NBS moves toward genetic screening (as opposed to, for example, testing analytes that could be affected by factors such as gestational age and birth weight ${ }^{42}$ ), the result could be greater precision in screening data, potentially reducing costs of unnecessary repeat or confirmatory tests and the associated parent anxiety. Of course the counterargument is that genetic screening has the potential to identify individuals with a genetic mutation, but for whom there are no clinical symptoms, creating a different kind of anxiety in parents who do not know whether their children will have a problem or not, ${ }^{43}$ a problem that will only be more complicated if whole exome or genome sequencing becomes part of NBS. ${ }^{44}$ We know that in the case of FX carriers, only a subset of individuals experience outcomes such as FXTAS or FXPOI or other health problems in adulthood, and there is currently no biomarker to differentiate who is or is not at additional risk for poor health, emotional, or learning outcomes.

\section{LESSON 7: POPULATION SCREENING PROVIDED A MORE ROBUST ESTIMATE OF PREVALENCE RATES FOR FMR1 PREMUTATION CARRIERS}

We found a premutation prevalence rate of 1 per 209 females and 1 per 430 males. ${ }^{27}$ These results are in general agreement with other recent population screening studies, suggesting that the prevalence of premutation alleles is higher than previous estimates. ${ }^{45-47}$ Full mutation alleles may be less common than previously reported; indeed, we identified only 1 male carrying the full mutation. However, a much larger sample size would be needed to obtain accurate estimates of full mutation prevalence. $^{48}$
A key requirement for NBS is understanding the true prevalence of a condition, to estimate the individual and public health burden of the disease, and to plan appropriately

for the scope of needed follow-up and support services. The only way to get accurate prevalence data is through population screening. Because only two-thirds of invited families chose to have their child screened, we cannot claim that this is a completely unbiased, representative sample, but the size and distribution of our sample give us more confidence in these data and add to the growing literature suggesting that premutation carriers are more common in the general population than earlier estimates. The implications of this finding are twofold. First, from a public health perspective, we now know that many more individuals in the general population are at risk for having a child with FXS or experiencing conditions, such as FXTAS or FXPOI, that are commonly associated with carrier status, creating a need for more awareness among clinicians and researchers to understand mechanisms and treatments. Second, from the perspective of NBS, the identification of premutation carriers poses a clear burden for which NBS counseling and follow-up programs are currently unprepared. For example, in North Carolina, which has a birth rate of $\sim 120000$ infants per year, we estimate that NBS would identify 15 boys and 15 girls with FXS per year (assuming a 1:4000 FXS prevalence rate). However, based on our prevalence estimates, a PCR-based test would also identify 140 boy and 287 girl carriers. NBS follow-up programs, primary care physicians, geneticists, and genetic counselors would face the challenge of providing information and counseling for a large number of families, genetic testing of other family members (both nuclear and extended), and surveillance and support throughout the childhood and adolescent years to monitor potential problems and help parents decide when to inform children of their carrier status and implications. 
LESSON 8: MOST SCREEN-POSITIVE BABIES WILL BE CARRIERS WITH LOW CGG REPEAT LENGTHS

Of the premutation carrier infants identified, we found that $\sim 70 \%$ carried an FMR1 allele with <70 CGG repeats, confirming preliminary results from other studies. ${ }^{28,45,49}$ This skewed distribution could have substantial implications for genetic counseling of carriers harboring smaller alleles, who may therefore have a lower risk of developing FXTAS and other psychiatric, cognitive, and motor problems. ${ }^{50-53}$ Analysis of AGG interruptions within the FMR1 gene is needed to determine allele stability and more accurately estimate the risk of expansion to a full mutation with transmission, which is particularly important in women with a premutation allele in the 55 to 70 range, adding to the complexity of follow-up genetic counseling in screen-positive cases. ${ }^{54,55}$ Infants with low CGG repeat lengths may have little risk themselves of having a child with the FMR1 full mutation, and their parents would likely have a CGG repeat length equal to or less than the infant's and also may have a relatively small chance of having a child with the full mutation, thus lessening the potential benefit from knowledge of reproductive risk and potentially raising greater uncertainty about multigenerational implications. However, premutation carriers may be at risk of presenting with neurodevelopmental problems even in the lower premutation range, ${ }^{21}$ and some data suggest a curvilinear pattern in which individuals with mid-range CGG repeats are at greater risk for health or mental health consequences than individuals with very short or very long repeats in the CGG repeat continuum. ${ }^{24,56-59}$ Unfortunately, we have imperfect knowledge about phenotype-genotype correlations within the carrier range, data that can only be gathered through systematic longitudinal research based on population screening of large samples. These data and accompanying ethical discussions and treatment studies ultimately are needed to guide decisions regarding CGG cut-offs to guide the return of results and the certainty of information for families.

\section{LESSON 9: FOLLOW-UP COUNSELING IS COMPLICATED, AND FAMILY PARTICIPATION IN DIAGNOSTIC CONFIRMATION AND LONGITUDINAL FOLLOW-UP WAS NOT UNIVERSAL}

A physician on the research team attempted to contact all families whose baby received a positive screen to offer genetic counseling and confirmatory testing. Families were then invited to a genetic counseling session where the results were reviewed, a family history was obtained, confirmatory testing was conducted with the infant, and other family members were offered testing if they wanted it. The initial phone call provided a reminder and context for the screening, which families did not always remember given the timing of the consent during the postpartum time frame, as well as the 6- to 8-week lag between the birth of the child and the results. of the 46 babies who screened positive for an FMR1 mutation (45 premutation, 1 full mutation), 30 received confirmatory testing and genetic counseling. Sixteen families did not receive follow-up counseling or confirmatory testing due to the following reasons: (1) they were unable to be reached by phone or mail ( $n=8)$; (2) they declined genetic counseling $(n=3)$ or repeat testing $(n=3)$; or (3) they did not show up for the appointment $(n=2)$.

The complex nature of inheritance and transmission of expansions in the FMR1 gene, the age-related penetrance and variable expressivity of pre- and full mutations, and comorbidities, such as anxiety in premutation carriers, contributed to the challenges of providing adequate genetic counseling and psychosocial support for screen-positive infants and their families. Multiple phone calls and clinic visits with the genetic counselor and geneticist were sometimes required.

Three of the screen-positive babies that were above the cutoff of 55 CGG repeats had confirmatory testing that showed 2 of them with a gray zone expansion (CGG $=50,51)$ and 1 with an allele in the normal range $(C G G=30)$. These false positives were determined to be due to a calibration error at the laboratory, which was quickly corrected. One additional boy infant's results indicated the presence of 2 FMR1 alleles, 1 of which had a premutation. Chromosome analysis confirmed the suspicion of 47, XXY (Klinefelter syndrome), and the family was counseled about both findings. Although rare, these false positive and secondary or unanticipated findings complicate the genetic counseling process.

Additional complicating matters for families is the pressure to inform other family members of their genetic risk. Extended family members may not hear about their potential to be a carrier until they interact with the primary family who received the information initially. Some extended family members may be grateful for the genetic counseling information even when the primary family may not be appreciative, whereas others would have preferred not to know.

All families who received confirmatory testing and genetic counseling were invited to participate in a longitudinal follow-up study. The longitudinal assessments consisted of quantitative measures and semistructured interviews to determine whether families experienced adverse mental health outcomes after a diagnosis and the extent to which they believed 
they were adequately informed about possible results from screening, were satisfied with their decision to participate, and whether and how their views about screening changed over time. In addition, measures of child social, cognitive, adaptive, emotional, and behavioral development were conducted. A sample of families whose children did not screen positive for FX, matched on ethnicity, language, education, and income with the sample of screenpositive families, was recruited as a comparison group. Assessments of the baby and family were conducted at 6-month intervals. Most of the families with a positive confirmatory test agreed to participate in at least 1 longitudinal assessment (26/28; 93\%). Six families received 1 evaluation, but did not respond to requests to schedule a second assessment. We found that having a developmental specialist present during the genetic counseling session to provide an initial assessment of the infant's development and discuss milestones tended to lead to greater participation in the longitudinal assessments.

The families who stayed in follow-up seemed to become more positive about their decision to participate as time went on because they felt they had an opportunity to ask questions and go over their child's development and behavior with the research team, including the psychologist and physician. They felt the visits were valuable based on the suggestions and reassurance they received during the study visits. If families received a diagnosis without options for this follow-up to occur, they might not be as positive about the information. This finding raises questions about the amount of resources needed to support families with children found to have a premutation for an extended period.
LESSON 10: MOTHERS OF IDENTIFIED BABIES DID NOT APPEAR TO HAVE WORSE MENTAL HEALTH OUTCOMES THAN MOTHERS OF SCREEN-NEGATIVE INFANTS

Of the many questions and concerns about FX NBS, one of the most persistent has been whether identifying premutation carriers would result in negative consequences for parents, especially for mothers who might experience increased postpartum depression, anxiety, or stress. ${ }^{16}$ We tested this assumption by conducting longitudinal assessments of these variables in mothers of identified children and compared their data with a matched sample of screennegative mothers. We found no significant group differences on measures of maternal anxiety, postpartum depression, parenting stress, or family quality of life.

Although these findings cannot necessarily be generalized to other families or situations, they provide important evidence suggesting that the anticipated harms of FX NBS may not be as likely as some have speculated. In part, this may be due to the thorough consent process, because we tried to make clear to parents the implications of deciding to participate in the study, and it is possible that the families more likely to have an adverse reaction may have been those who opted out of the study initially or who did not participate in the longitudinal study. Nonetheless, it is important to know that it is possible to offer screening in a way that minimizes the likelihood of adverse reactions.

\section{DISCUSSION}

Despite the scope and enormity of effort required to implement this study, several limitations must be acknowledged. First, although we offered screening to thousands of families and screened thousands of babies, the sample size remains small for answering questions, such as the prevalence of full mutation infants, ethnic variation in CGG repeat expansion in the full mutation range, family adaptation, and infant developmental status. Second, the study was limited to 3 universitybased hospitals, and although the patient populations in these hospitals were quite diverse, the findings may not be generalizable to the United States more broadly. Third, there may be family characteristics that we did not assess that could have contributed to parents' willingness to have their baby screened, and the parents who agreed to participate in the longitudinal study may be different from those who did not (although we found no differences in maternal age, marital status, race/ ethnicity, maternal education, and CGG repeat length of the identified child). ${ }^{60}$ Finally, the study was not designed to prove benefit for children and, as such, does not answer the ultimate question of whether FX NBS is good public policy.

Nonetheless, the study provides answers to a number of heretofore unanswered questions, and hopefully advances the field toward a better understanding of the nature and consequences of offering FX NBS. What research or other discoveries are now needed to determine whether and how NBS should be offered for FXS? In a companion article in this supplement, "Implications of the FMR1 Premutation for Children, Adolescents, Adults, and Their Families," Wheeler et al identify issues and barriers related to NBS for FXS and present the strengths and challenges of potential approaches to addressing them. As with all rare diseases, each question would require a considerable investment to answer. Because most candidate conditions are rare, the challenges that must be overcome to provide the necessary evidence base are enormous. Classic criteria for NBS 
include a thorough understanding of first symptoms, early phenotypic expression, the life course of the disease, genotype-phenotype correlations, and the efficacy of presymptomatic treatments. But researchers seeking to provide this information are caught in a classic "catch 22" situation: screening cannot be justified because of insufficient research, but the research that must be conducted is impossible without some sort of population screening. Unfortunately, there is no clear mechanism for prioritizing these issues, but it seems logical that advances would be most efficacious if a deliberative strategy could be identified and teams of investigators could work together to solve them. Ultimately, a standing resource for evaluating candidate conditions for NBS could expedite needed research to answer pressing policy issues and provide the data needed before conditions can be recommended for inclusion in state NBS programs. ${ }^{61}$
In the meantime, families continue to experience problems and frustrations in the delayed diagnosis of children with FXS, and a number of practical strategies have been suggested to advance earlier identification. ${ }^{62}$ Certainly, better training for physicians and other health professionals in conducting regular developmental screenings and responding to parents' concerns would help, but FXS is so nonspecific in its presentation that any symptom-based approach to earlier identification would probably have a limited impact on the age of diagnosis. Population screening in some form will likely be the only realistic way to identify early all children with FX mutations for their benefit and the benefit of their families.

\section{ACKNOWLEDGMENTS}

We thank the families who participated in this study and the many members of our research teams, including Debra Skinner, Leah Barnum, Allen Buansi, Summer Choudhury, Carly Gasior, Kylee Miller, Anna DeSonia, Myra Roche, Christina Prescot, Susan Rohde, John Sideris, and Page Sorensen.

\section{ABBREVIATIONS}

\author{
FX: fragile $\mathrm{X}$ \\ FXPOI: FX-associated primary \\ ovarian insufficiency \\ FXS: fragile $\mathrm{X}$ syndrome \\ FXTAS: FX-associated tremor \\ ataxia syndrome
}

IDM: informed decision-making

IRB: institutional review board

NBS: newborn screening

PCR: polymerase chain reaction

RUMC: Rush University Medical Center

UC-Davis: University of California, Davis

UNC-CH: University of North Carolina at Chapel Hill

Copyright @ 2017 by the American Academy of Pediatrics

FINANCIAL DISCLOSURE: Dr Bailey discloses other current funding from Ovid Therapeutics and The John Merck Fund; Dr Berry-Kravis discloses current or recent funding from Seaside Therapeutics, Novartis, Roche, Neuren, and Alcobra Pharmaceuticals to consult on trial design and conduct clinical trials in fragile $X$ syndrome (FXS) and from Asuragen, Inc to develop standards for FMR1 testing; Dr Hagerman discloses recent consultations with Roche, Novartis, and Alcobra Pharmaceuticals regarding trials in patients with FXS and with Down syndrome and is currently carrying out clinical trials in FXS with Alcobra and Neuren; and the other authors have indicated they have no financial relationships relevant to this article to disclose.

FUNDING: This study was supported by the Eunice Kennedy Shriver National Institute for Child Health and Human Development (grants P30 HD003110-S1, R01HD02274, and 3P30HD02274-35S1); the National Human Genome Research Institute's Ethical, Legal, and Social Implications Research Program (grant 5P50HG004488); Centers for Disease Control and Prevention in conjunction with the Association for Prevention Teaching and Research (cooperative agreement U50/CCU300860, project TS-1470); the National Newborn Screening and Genetics Resource Center, a cooperative agreement between the Maternal and Child Health Bureau, Genetic Services Branch and the Department of Pediatrics, University of Texas Health Science Center at San Antonio; the Health Resources and Services Administration (grant U32-MC00148); and the National Center of Research Resources, National Institutes of Health (grant UL1RR02574). Funded by the National Institutes of Health (NIH).

POTENTIAL CONFLICT OF INTEREST: Dr Bailey discloses current other funding from Ovid Therapeutics and the John Merck Fund; Dr Berry-Kravis discloses current or recent funding from Seaside Therapeutics, Novartis, Roche, Neuren, and Alcobra Pharmaceuticals to consult on trial design and conduct clinical trials in fragile X syndrome (FXS) and from Asuragen, Inc to develop standards for FMR1 testing; Dr Hagerman discloses recent consultations with Roche, Novartis, and Alcobra Pharmaceuticals regarding trials in patients with FXS and with Down syndrome and is currently carrying out clinical trials in FXS with Alcobra and Neuren; and the other authors have indicated they have no potential conflicts of interest to disclose

\section{REFERENCES}

1. Bailey DB Jr, Raspa M, Olmsted M, Holiday DB. Co-occurring conditions associated with FMR1 gene variations: findings from a national parent survey. Am J Med Genet A. 2008;146A(16):2060-2069

2. Bailey DB, Skinner D, Hatton D, Roberts J. Family experiences and factors associated with the diagnosis of fragile X syndrome. J Dev Behav Pediatr. 2000;21(5):315-321

3. Bailey DB Jr, Skinner D, Sparkman $\mathrm{KL}$. Discovering fragile $\mathrm{X}$ syndrome: family experiences and perceptions. Pediatrics. 2003;111(2): 407-416
4. Bailey DB Jr, Raspa M, Bishop E, Holiday D. No change in the age of diagnosis for fragile $x$ syndrome: findings from a national parent survey. Pediatrics. 2009;124(2): $527-533$

5. Skinner D, Sparkman KL, Bailey DB Jr. Screening for fragile $X$ syndrome: 
parent attitudes and perspectives. Genet Med. 2003;5(5):378-384

6. Bailey DB Jr, Bishop E, Raspa M, Skinner D. Caregiver opinions about fragile $X$ population screening. Genet Med. 2012;14(1):115-121

7. Christie L, Wotton T, Bennetts B, et al. Maternal attitudes to newborn screening for fragile $\mathrm{X}$ syndrome. Am J Med Genet A. 2013;161A(2):301-311

8. Acharya K, Ackerman PD, Ross LF. Pediatricians' attitudes toward expanding newborn screening. Pediatrics. 2005;116(4). Available at: www.pediatrics.org/cgi/content/full/ 116/4/e476

9. Hiraki S, Ormond KE, Kim K, Ross LF. Attitudes of genetic counselors towards expanding newborn screening and offering predictive genetic testing to children. $A m$ J Med Genet A. 2006;140(21): 2312-2319

10. Kemper AR, Bailey DB Jr. Pediatricians' knowledge of and attitudes toward fragile $X$ syndrome screening. Acad Pediatr. 2009;9(2):114-117

11. Acharya K, Ross LF. Fragile $X$ screening: attitudes of genetic health professionals. Am J Med Genet A. 2009;149A(4):626-632

12. Acharya K, Schindler A. Developmental and behavioral pediatricians' attitudes toward screening for fragile X. Am J Intellect Dev Disabil. 2013;118(4):284-293

13. Bailey DB Jr. Newborn screening for fragile X syndrome. Ment Retard Dev Disabil Res Rev. 2004;10(1):3-10

14. Bailey DB. Newborn screening for intellectual disability: Past, present, and future. In: Glidden LM, ed. International Review of Research in Mental Retardation. Burlington, MA: Academic Press; 2008:1-25

15. Kemper AR, Green NS, Calonge N, et al. Decision-making process for conditions nominated to the recommended uniform screening panel: statement of the US Department of Health and Human Services Secretary's Advisory Committee on Heritable Disorders in Newborns and Children. Genet Med. 2014;16(2):183-187
16. Bailey DB Jr, Skinner D, Davis AM, Whitmarsh I, Powell C. Ethical, legal, and social concerns about expanded newborn screening: fragile $X$ syndrome as a prototype for emerging issues. Pediatrics. 2008;121(3). Available at: www.pediatrics.org/cgi/content/full/ 121/3/e693

17. Ross LF. Ethical and policy issues in newborn screening of children for neurologic and developmental disorders. Pediatr Clin North Am. 2015;62(3):787-798

18. Committee on Bioethics; Committee on Genetics; American College of Medical Genetics ; Genomics Social, Ethical, Legal Issues Committee. Ethical and policy issues in genetic testing and screening of children. Pediatrics. 2013;131(3):620-622

19. Ross LF, Saal HM, David KL, Anderson RR; American Academy of Pediatrics; American College of Medical Genetics and Genomics. Technical report: ethical and policy issues in genetic testing and screening of children [published correction appears in Genet Med. 2013;15(4):321]. Genet Med. 2013;15(3):234-245

20. Sherman SL, Curnow EC, Easley $\mathrm{CA}$, et al. Use of model systems to understand the etiology of fragile $X$-associated primary ovarian insufficiency (FXPOI). J Neurodev Disord. 2014;6(1):26

21. Hagerman R, Hagerman P. Advances in clinical and molecular understanding of the FMR1 premutation and fragile $X$-associated tremor/ataxia syndrome. Lancet Neurol. 2013;12 (8):786-798

22. Wheeler AC, Bailey DB Jr, Berry-Kravis $E$, et al. Associated features in females with an FMR1 premutation. J Neurodev Disord. 2014;6(1):30

23. Grigsby J, Cornish K, Hocking D, et al. The cognitive neuropsychological phenotype of carriers of the FMR 1 premutation. J Neurodev Disord. 2014;6(1):28

24. Roberts JE, Tonnsen BL, McCary LM, et al. Trajectory and predictors of depression and anxiety disorders in mothers with the FMR1 premutation. Biol Psychiatry. 2016;79(10):850-857

25. Farzin F, Perry H, Hessl D, et al. Autism spectrum disorders and attention-deficit/hyperactivity disorder in boys with the fragile $X$ premutation. J Dev Behav Pediatr. 2006;27 (suppl 2):S137-S144

26. Chonchaiya W, Au J, Schneider A, et al. Increased prevalence of seizures in boys who were probands with the FMR1 premutation and co-morbid autism spectrum disorder. Hum Genet. 2012;131(4):581-589

27. Skinner D, Choudhury S, Sideris J, et al. Parents' decisions to screen newborns for FMR1 gene expansions in a pilot research project. Pediatrics. 2011;127 (6). Available at: www. pediatrics.org/cgi/content/full/127/6/ e1455

28. Tassone F, long KP, Tong TH, et al. FMR1 CGG allele size and prevalence ascertained through newborn screening in the United States. Genome Med. 2012;4(12):100

29. Feuchtbaum L, Cunningham G, Sciortino S. Questioning the need for informed consent: a case study of California's experience with a pilot newborn screening research project. J Empir Res Hum Res Ethics. 2007;2(3):3-14

30. Tarini BA, Burke W, Scott CR, Wilfond BS. Waiving informed consent in newborn screening research: balancing social value and respect. Am J Med Genet C Semin Med Genet. 2008;148C(1):23-30

31. Ross LF. Mandatory versus voluntary consent for newborn screening? Kennedy Inst Ethics J. 2010;20(4):299-328

32. Grady C. Enduring and emerging challenges of informed consent. $N$ Engl J Med. 2015;372 (9):855-862

33. US Department of Health and Human Services. Protection of human subjects. Additional protections for children involved as subjects in research. 45 CFR $\S 46$, subpart D. Revised June 18, 1991. Available at: www.hhs.gov/ohrp/regulations-andpolicy/regulations/45-cfr-46/

34. Nelson DK, Skinner D, Guarda S, et al. Obtaining consent from both parents for pediatric research: what does "reasonably available" mean? Pediatrics. 2013;131(1). Available at: 
www.pediatrics.org/cgi/content/full/ 131/1/e223

35. Sorensen PL, Gane LW, Yarborough M, Hagerman RJ, Tassone F. Newborn screening and cascade testing for FMR1 mutations. Am J Med Genet $A$. 2013;161A(1):59-69

36. O'Connor AM, Bennett CL, Stacey D, et al. Decision aids for people facing health treatment or screening decisions. Cochrane Database Syst Rev. 2009;(3):CD001431

37. Elwyn G, Frosch D, Volandes AE, Edwards A, Montori VM. Investing in deliberation: a definition and classification of decision support interventions for people facing difficult health decisions. Med Decis Making. 2010;30(6):701-711

38. Bailey DB Jr, Lewis MA, Harris SL, et al. Design and evaluation of a decision aid for inviting parents to participate in a fragile $X$ newborn screening pilot study. J Genet Couns. 2013;22(1):108-117

39. Bailey DB Jr, Bann C, Bishop E, Guarda $S$, Barnum L, Roche M. Can a decision aid enable informed decisions in neonatal nursery recruitment for a fragile $X$ newborn screening study? Genet Med. 2013;15(4):299-306

40. Sorenson JR, Lakon C, Spinney T, Jennings-Grant T. Assessment of a decision aid to assist genetic testing research participants in the informed consent process. Genet Test. 2004;8(3):336-346

41. Tassone F, Pan R, Amiri K, Taylor AK, Hagerman PJ. A rapid polymerase chain reaction-based screening method for identification of all expanded alleles of the fragile $X$ (FMR1) gene in newborn and high-risk populations. J Mol Diagn. 2008;10(1):43-49

42. Slaughter JL, Meinzen-Derr J, Rose $\mathrm{SR}$, et al. The effects of gestational age and birth weight on false-positive newborn-screening rates. Pediatrics. 2010;126(5):910-916

43. Timmermans S, Buchbinder M. Patients-in-waiting: living between sickness and health in the genomics era. J Health Soc Behav. 2010;51(4):408-423
44. Goldenberg AJ, Sharp RR. The ethical hazards and programmatic challenges of genomic newborn screening. JAMA. 2012;307(5):461-462

45. Hantash FM, Goos DM, Crossley B, et al. FMR1 premutation carrier frequency in patients undergoing routine population-based carrier screening: insights into the prevalence of fragile $X$ syndrome, fragile $X$-associated tremor/ataxia syndrome, and fragile X-associated primary ovarian insufficiency in the United States. Genet Med. 2011;13(1):39-45

46. Seltzer MM, Baker MW, Hong J, Maenner M, Greenberg J, Mandel D. Prevalence of CGG expansions of the FMR1 gene in a US population-based sample. Am J Med Genet $B$ Neuropsychiatr Genet. 2012;159B (5):589-597

47. Maenner MJ, Baker MW, Broman KW, et al. FMR1 CGG expansions: prevalence and sex ratios. Am J Med Genet $B$ Neuropsychiatr Genet. 2013;162B(5):466-473

48. Coffee B, Keith K, Albizua I, et al. Incidence of fragile $X$ syndrome by newborn screening for methylated FMR1 DNA. Am J Hum Genet. 2009;85(4):503-514

49. Toledano-Alhadef H, Basel-Vanagaite L, Magal N, et al. Fragile-X carrier screening and the prevalence of premutation and full-mutation carriers in Israel. Am J Hum Genet. 2001;69(2):351-360

50. Jacquemont S, Leehey MA, Hagerman RJ, Beckett LA, Hagerman PJ. Size bias of fragile X premutation alleles in late-onset movement disorders. J Med Genet. 2006;43(10):804-809

51. Kraan CM, Hocking DR, GeorgiouKaristianis N, et al Age and CGG-repeat length are associated with neuromotor impairments in at-risk females with the FMR1 premutation. Neurobiol Aging. 2014;35(9): 2179.e7-2179.e13

52. Loesch DZ, Bui MQ, Hammersley E, et al. Psychological status in female carriers of premutation FMR1 allele showing a complex relationship with the size of CGG expansion. Clin Genet. 2015;87(2):173-178
53. Goodrich-Hunsaker NJ, Wong LM, McLennan $Y$, et al. Adult female fragile $X$ premutation carriers exhibit age- and CGG repeat length-related impairments on an attentionally based enumeration task. Front Hum Neurosci. 2011;5:63

54. Nolin SL, Glicksman A, Ersalesi N, et al. Fragile $X$ full mutation expansions are inhibited by one or more AGG interruptions in premutation carriers. Genet Med. 2015;17(5):358-364

55. Yrigollen CM, Martorell L, DurbinJohnson B, et al. AGG interruptions and maternal age affect FMR1 CGG repeat allele stability during transmission. J Neurodev Disord. 2014;6(1):24

56. Seltzer MM, Barker ET, Greenberg JS, Hong J, Coe C, Almeida D. Differential sensitivity to life stress in FMR1 premutation carrier mothers of children with fragile $X$ syndrome. Health Psychol. 2012;31(5):612-622

57. Sullivan AK, Marcus M, Epstein MP et al. Association of FMR1 repeat size with ovarian dysfunction. Hum Reprod. 2005;20(2):402-412

58. Ennis S, Ward D, Murray A. Nonlinear association between CGG repeat number and age of menopause in FMR1 premutation carriers. Eur J Hum Genet. 2006;14(2):253-255

59. Mailick MR, Hong J, Greenberg J, Smith L, Sherman S. Curvilinear association of CGG repeats and age at menopause in women with FMR1 premutation expansions. Am J Med Genet B Neuropsychiatr Genet. 2014;165B(8):705-711

60. Bailey DB Jr, Wheeler A, Berry-Kravis $E$, et al. Maternal consequences of the detection of fragile $\mathrm{X}$ carriers in newborn screening. Pediatrics. 2015;136(2). Available at: www pediatrics.org/cgi/content/full/136/2/ e433

61. Bailey DB Jr, Gehtland L. Newborn screening: evolving challenges in an era of rapid discovery. JAMA. 2015;313(15):1511-1512

62. Abrams L, Cronister A, Brown WT, et al. Newborn, carrier, and early childhood screening recommendations for fragile X. Pediatrics. 2012;130(6):1126-1135 


\section{Fragile X Newborn Screening: Lessons Learned From a Multisite Screening Study}

Donald B. Bailey Jr, Elizabeth Berry-Kravis, Louise W. Gane, Sonia Guarda, Randi Hagerman, Cynthia M. Powell, Flora Tassone and Anne Wheeler

Pediatrics 2017;139;:S216

DOI: $10.1542 /$ peds.2016-1159H

\begin{tabular}{|c|c|}
\hline $\begin{array}{l}\text { Updated Information \& } \\
\text { Services }\end{array}$ & $\begin{array}{l}\text { including high resolution figures, can be found at: } \\
\text { http://pediatrics.apppublications.org/content/139/Supplement_3/S216 }\end{array}$ \\
\hline References & $\begin{array}{l}\text { This article cites } 60 \text { articles, } 11 \text { of which you can access for free at: } \\
\text { http://pediatrics.aappublications.org/content/139/Supplement_3/S216 } \\
\text { \#BIBL }\end{array}$ \\
\hline Permissions \& Licensing & $\begin{array}{l}\text { Information about reproducing this article in parts (figures, tables) or } \\
\text { in its entirety can be found online at: } \\
\text { http://www.aappublications.org/site/misc/Permissions.xhtml }\end{array}$ \\
\hline Reprints & $\begin{array}{l}\text { Information about ordering reprints can be found online: } \\
\text { http://www.aappublications.org/site/misc/reprints.xhtml }\end{array}$ \\
\hline
\end{tabular}




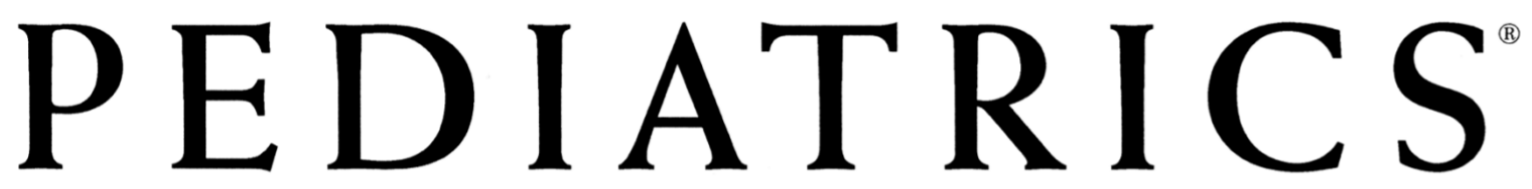

OFFICIAL JOURNAL OF THE AMERICAN ACADEMY OF PEDIATRICS

Fragile X Newborn Screening: Lessons Learned From a Multisite Screening Study

Donald B. Bailey Jr, Elizabeth Berry-Kravis, Louise W. Gane, Sonia Guarda, Randi Hagerman, Cynthia M. Powell, Flora Tassone and Anne Wheeler

Pediatrics 2017;139;S216

DOI: $10.1542 /$ peds.2016-1159H

The online version of this article, along with updated information and services, is located on the World Wide Web at:

http://pediatrics.aappublications.org/content/139/Supplement_3/S216

Pediatrics is the official journal of the American Academy of Pediatrics. A monthly publication, it has been published continuously since 1948. Pediatrics is owned, published, and trademarked by the American Academy of Pediatrics, 141 Northwest Point Boulevard, Elk Grove Village, Illinois, 60007. Copyright $@ 2017$ by the American Academy of Pediatrics. All rights reserved. Print ISSN: 1073-0397.

\section{American Academy of Pediatrics}

